\title{
The Impact of Organizational Commitment as a Mediator Variable on the Relationship between the Internal Marketing and Internal Service Quality: An Empirical Study of Five Star Hotels in Amman
}

\author{
Ghassan R. Odeh ${ }^{1} \&$ Hamad R. Alghadeer ${ }^{2}$ \\ ${ }^{1}$ Business Development Manager, Makeen Co., Jordan \\ ${ }^{2}$ Faculty of Economics and Administrative Science, Applied Science University, Amman, Jordan \\ Correspondence: Ghassan R. Odeh, Business Development Manager, Makeen Co., Jordan. Tel: \\ 962-79-689-4229. E-mail: ghassan_aggassi@hotmail.com
}

\author{
Received: February 8, 2014 Accepted: April 10, $2014 \quad$ Online Published: May 21, 2014 \\ doi:10.5539/ijms.v6n3p142 URL: http://dx.doi.org/10.5539/ijms.v6n3p142
}

\begin{abstract}
This study aimed to identify the relationship between internal marketing and internal service quality, also this study came to identify the mediating role of organizational commitment in the relationship between internal marketing and internal service quality. Sample of the study consisted of (202) workers in the five star hotels in Amman. The results showed that

There was a statistically significant impact for the internal marketing on the reliability of five star hotels in Amman. These results indicate that there was an impact for internal marketing on reliability. And also there was a statistically significant impact for the internal marketing on the responsiveness of five star hotels in Amman.
\end{abstract}

Keywords: internal marketing, internal service quality, organizational commitment, five star hotels

\section{Introduction}

Dennis (1995) claimed that internal marketing is a strategic management approach which attracts, develops, motivates, and maintains employees by providing work products satisfying employees' needs. A common view among researchers supports the role of internal marketing as encouraging employees to adopt and display market orientated behavior. Gronroos (1990) suggested that internal marketing can change employee's attitude and behaviors, and establish the corporate culture. Accordingly, Lee and Chen (2005) examined the relationship between internal marketing and organizational culture and found a significant impact of internal marketing on organizational culture.

Here, the role of internal marketing in providing a high quality services emerges. In essence, internal marketing recognizes and acknowledges that all employees are customers of managers and employers wishing to carry out the firm's objectives and achieve them. If the firm's objectives are sound from an external marketing standpoint, individual functional areas contribute by responding to their respective internal publics, each of which is directly or indirectly linked to the ultimate customer and competitive marketplace (Harrell, Fors, 1995). Internal marketing is defined as "the task of hiring, training and motivating the employees who want to serve the customers well". In fact, internal marketing must precede external marketing. It makes no sense to promise excellent service before the company itself is ready to provide it (Kotler\& Armstrong, 2007, p. 260).

External marketing is the result of the internal marketing activities carried out within the internal marketing activities in the organization. As known, internal marketing focuses mainly on qualifying and increasing the competency of workers within a given organization in order to promote the quality of services provided for different customers. This is especially true for the service industry as it all concerned with providing high quality services for different customers in order to meet their initial expectations (Kotler \& Armstrong, 2007).

\section{Litreature Review}

\subsection{Internal Marketing}

Many researchers pay attention for the internal marketing because it is a fundamental part in the organization, internal marketing refers to the employees who work in the organization, and when the internal marketing got 
satisfied, the whole organization will get satisfied. As shown in this study by Chang and Chang (2009) conducted a study to determine whether a favorable perception of internal marketing is associated with increased organizational commitment. The role of nurses in healthcare treatment is expanding, and becoming more important as time progresses. Therefore, the primary concern of business of health care is to use internal marketing strategies effectively to enhance and develop nurses' organizational commitment and reduce turnover to promote competitive advantages for the organization. A cross-sectional design was used. Questionnaires were distributed in 2006 to a convenience sample of (450) of registered nurses in two teaching hospitals in Taiwan. (318) usable questionnaires were returned. Eighteen were excluded because of incomplete answers, which left (300) usable questionnaires (response rate 66.7\%).Validity and reliability testing of the questionnaire proved satisfactory and Structural Equation Modeling was used to analyze the data. A favorable perception of internal marketing was associated with increased organizational commitment. Communication management had the greatest influence on organizational commitment and external activity had the smallest impact. Hospital managers need to recognize the importance of internal marketing for staff retention and the survival of their organizations as competitive pressure increases. As a great deal of time and costs are involved in educating nurses, the best way to retain outstanding nurses and reduce turnover costs and personnel problems is for employers to understand the needs and expectations of their nursing staff.

\subsection{Internal Service Quality}

Pfau et al. (1991) and Albrecht (1993) defined internal service quality as a potential source of sustainable competitive advantage. Gaspari and Elmazi (2011) indicated in their study that the importance of service quality for tourism and hospitality businesses is gaining tremendous attention. In order to provide quality service to the customers, knowledge of their service quality expectations is considered very important. Results of the study indicated a significant correlation between operational quality which is linked to the performer of the service, and perceived quality which is linked to consumer of the service respectively. The study confirmed the role of triangle marketing in improvement of tourist quality service. Triangle marketing directly and indirectly served to narrow the gaps in service quality. Delivery of quality service in tourism required cooperation from employees, management and customers.

\subsection{Organizational Commitment}

The successful way to increase sales and money in the organization is to manage the whole organization, the organization should motive the employees by either rewards, and incentives to keep them working hard and in commitment way.

Cobanand Perçin (2011) investigated the effects of factors of internal marketing on components of organizational commitment in four and five star hotels in Cappadocia (Nevsehir). The questionnaire prepared for this purpose was applied on the hotel employees. The data were analyzed through factor analysis and regression analysis. The findings of the research show that communication, rewards and cooperation-integration factors were significant predictors of affective commitment, and cooperation-integration, communication, rewards and motivation policies had a significant positive effect on normative commitment. Also, it can be said that motivation factor has a positive effect on continuance commitment. According to research findings, it is advised that managers should use internal communication methods efficiently as strategic tool to strengthen affective and normative commitment among employees.

\subsection{Internal Marketing, Service Quality, and Internal Service Quality}

The relationship between internal marketing, internal service quality and organizational commitment is well documented. For example, Bai, Brewer, and Swerdlow (2006) conducted a study which aimed to create a case study in employee attitudes on job satisfaction in a hotel/casino in Las Vegas, Nevada. The researchers investigated the discrete level of their job satisfaction, internal service quality and their relationship with employees' organizational commitment. The results of the study indicated significant relationships between employees' job satisfaction, internal service quality and their organizational commitment, thus, the level of job satisfaction and organizational commitment among employees played a vital role in the level of service quality provided by the employees in hotels and casinos in Las Vegas.

Another study, Atousa, Nasimand Albert (2008) Investigated in their study the effects of internal marketing criteria on organizational commitment of employees among Iranian state-owned banks. Internal marketing is a planned effort using a marketing-like approach to overcome organizational resistance to change and to align, motivate and inter-functionally co-ordinate and integrate employees towards the effective implementation of corporate and functional strategies which is growing recognition with the increasing competition and commoditization of products and services. The main criteria of internal marketing were derived from the 
literature, provided the backbone for the study. A questionnaire survey of managers established that "inter-functional coordination and integration", training and motivation have positive effects on organizational commitment of employees. Therefore if the state-owned banks want to ultimately provide a better service experience for their customers; it is recommended that more attention be directed toward enhancing organizational commitment among personnel, with a focus on the effective criteria of internal marketing.

In other study, Tsai, and Tang (2008) investigated the relationship between three internal marketing practices and service quality. The authors used a cross-sectional design to examine the relationship between internal marketing and service quality with structural equation modeling. The results of the research clearly showed that there are significant positive relationships between internal marketing practices and service quality. In particular, the results of the present research demonstrate that training programs have a strong association with service quality. However, the relationship from performance incentives to service quality was not found. Consequently, to deliver excellence service to patients, a hospital must provide training programs and establish a clear vision about service excellence to nurses.

\section{Hypotheses}

Ho.1: There is no statistically significant impact of overall dimensions of internal marketing on the overall internal service quality dimensions of five star hotels in Amman.

H0.1.1: There is no statistically significant impact for the overall dimensions of internal marketing on the reliability of five star hotels in Amman.

H0. 1.2: There is no statistically significant impact for the overall dimensions of internal marketing on the responsiveness of five star hotels in Amman.

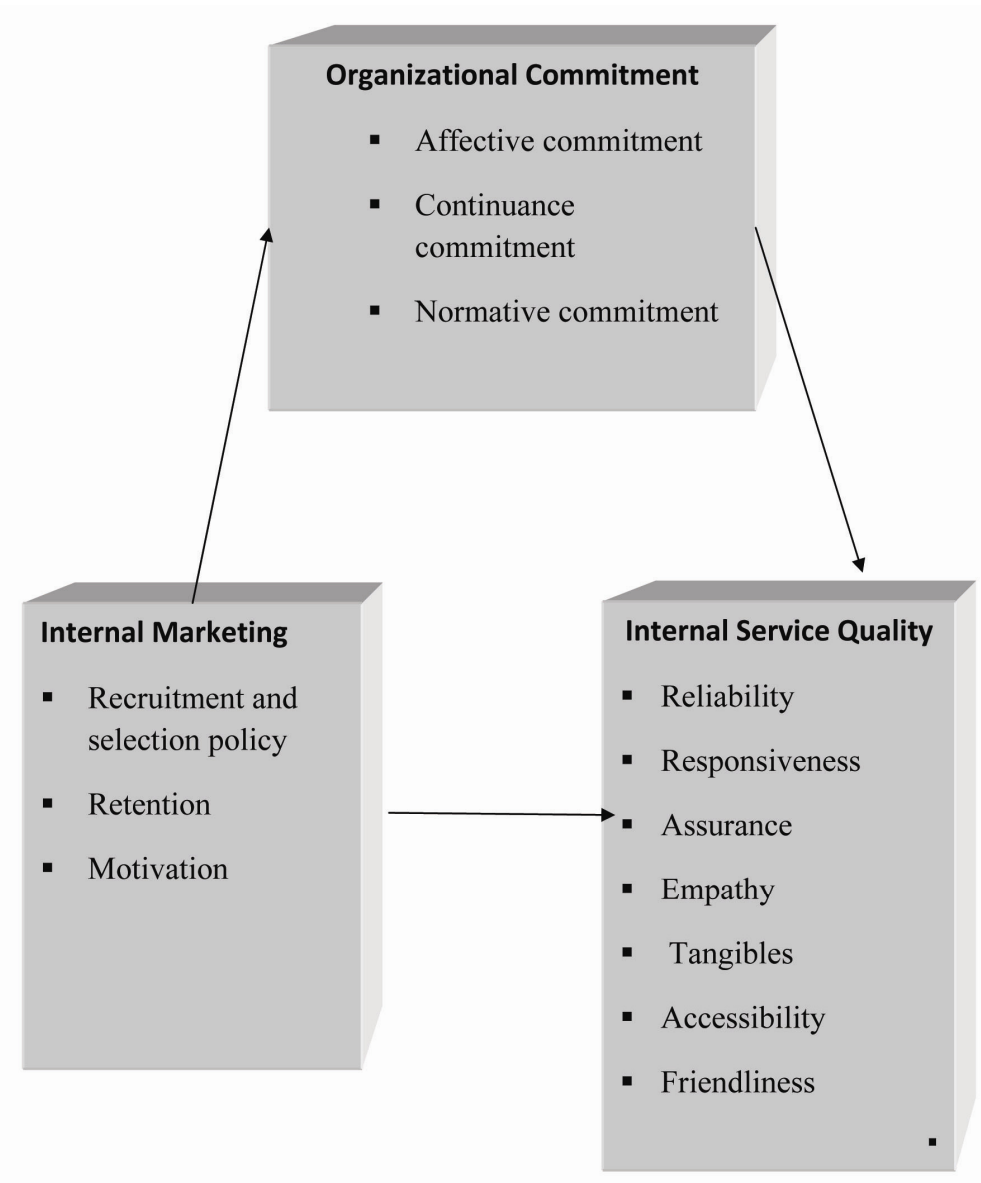

Figure 1. Model of the study 


\section{Research Objectives}

1) To identify the impact of internal marketing on internal service quality?

2) To identify the impact of the overall dimensions of internal marketing on reliability of five star hotels in Amman?

3) To identify the impact of the overall dimensions of internal marketing on responsiveness of five star hotels in Amman?

\section{Research Methodology}

\subsection{Population and Sample}

Population of the study consisted of all employees working in five- star hotels at Amman in 2012, after many visits to these hotels, then five stars hotel were selected for the purpose of the study. The hotels were six as the following: Le Royal, Regency Palace, Kempinski Hotel, Millennium Hotel, Sheraton Hotel, Landmark Hotel. A convenient sample from the population of the study, were selected. As known, a convenient sample is one of the easiest sampling procedures used in the marketing literature. As such, the researcher went to the sampled five star hotels and distributed the instruments of the study to the employees he found when going to the sampled hotels. (384) questionnaires were distributed, and only (202) respondents questionnaire were valid for this study, because some of the hotels did not cooperate with the researcher in this regard. The questionnaire was disturbed in February 2013.

\subsection{Data Collection}

The data has been collected through two ways either primary or secondary data as mentioned below: Secondary data such as reviewing previous literature, books, periodicals and publications relating to internal. And Primary data: A questionnaire consisted of three domains: internal marketing, internal service quality and organizational commitment for data collecting from the sample subjects.

\section{Results and Discussion}

H0.1: There is no statistically significant impact of overall dimensions of internal marketing on the overall internal service quality dimensions of five star hotels in Amman.

To test this hypothesis the researcher performed multiple regressions. Multiple regression analysis was performed and the results of the analysis, as shown above, F value equal (60.864) at sig. (0.00). The researcher rejected the null hypothesis and accepted the alternative hypothesis stating that "There is statistically significant impact of the overall dimensions of internal marketing on the internal service quality dimensions in Jordanian five star hotels in Amman". And this results confirmed by the value of $t=(13.462)$ at sig $(0.00)$ for recruitment and selection, and motivation with sig $(0.00)$, but the results showed there is no statistical impact on retention in which sig were above (0.05). In addition R2 was (.480), meaning that (48\%) of changes taking place in study subjects means scores about internal service quality due to internal marketing.

H0.1.1: There is no statistically significant impact for the overall dimensions of internal marketing on the reliability of five star hotels in Amman.

Linear regression analysis was performed and the results of the analysis, F value equal (37.766) at sig. (0.00). The researcher rejected the null hypothesis and accepted the alternative hypothesis stating that "There is statistically significant impact for the overall dimensions of internal marketing on reliability of five star hotels in Amman". And this results confirmed by the value of $t=(6.145)$ at sig $(0.00)$, which is less than $(0.05)$. In addition $\mathrm{R}^{2}$ was $(0.159)$, meaning that $15.9 \%$ of changes taking place in study subjects means scores about internal service quality due to internal marketing.

H0.1.2: There is no statistically significant impact for the overall dimensions of internal marketing on the responsiveness of five star hotels in Amman.

Linear regression analysis was performed and the results of the analysis, F value equal (293.745) at sig. (0.00). The researcher rejected the null hypothesis and accepted the alternative hypothesis stating that "There is statistically significant impact for the all dimensions of internal marketing on the responsiveness of five star hotels in Amman". And this results confirmed by the value of $\mathrm{t}=(17.139)$ at sig $(0.00)$, which is less than $(0.05)$. In addition $\mathrm{R}^{2}$ was $(0.595)$, meaning that $59.5 \%$ of changes taking place in study subjects means scores about Responsiveness due to internal marketing. 


\section{Implications}

This study is going to help organizations to increase their sales and market share through motive and train employees to get more commitment to the organization and to keep them work more and more harder, and also this will help researcher to start from this point which the commitment.

\section{Conclusion}

From the study results, it showed that the means for the study main domains were ranked from moderate to high. The internal service quality got the highest rank, then the Organizational Commitment, at the final rank the internal marketing were with moderate rank. These positive results from the researcher point view, is due to the increases in competition severity and growth of the human needs, so the hotel administrations is taking care of internal marketing and internal service quality and organizational commitment. These results are similar to the results of Aladwan (2011).

Also the results showed that the sub domains were ranged from moderate to high degree, which the domain Reliability got the highest rank with high means, then domain "Accessibility" and at the third rank the domain "Friendliness" with mean also the results showed that "retention" got the lowest mean with moderate rank, and at the final rank the domain Continuance Commitment".

From the researcher point of view that the hotel employees is trying their best to achieve and perform hotel vision and goals in a reliable way, and this is due to that the hotel administration practices like employee motivation, training, and good service providing

From the researcher point of view the reliability items is necessary for achieving work goals and aims, by providing good environment and communications skills between workers in the hotel. Also this result indicates that that the hotel employees are aware of problem solving in the hotel, and accomplishing the tasks in a good way.

Also the results indicates that the hotel administrating is practicing good management, in which these management is trying to motivate employees with both moral or material incentives, also with some exceptions like some retention items, which show that some employee think of leaving the hotel if they got another chance or better salary, but the results showed also that there is a minimum options for these employees to leave the hotel.

The study results showed that there is statistically significant impact of the overall dimensions of internal marketing on overall dimensions of internal service quality of five star hotels in Amman.

These impacts of internal marketing on internal service quality, from the researcher point view is due to that hotel administration have a good knowledge that success comes from employees and customers satisfaction. Also to achieve customers' satisfaction, first we must provide workers satisfaction, and increase their performance by different ways.

\section{References}

Aburoub, A., Hersh, A., \& Aladwan, K. (2011). Relationship between Internal Marketing and Service Quality with Customers' Satisfaction. International Journal of Marketing Studies, 3(2), 107-120.

Atousa, F., Nasim, N., \& Albert, C. (2008). The Effect of Internal Marketing on Organizational Commitment in Iranian Banks. American Journal of Applied Sciences, 5(11), 1480-1486. http://dx.doi.org/10.3844/ajassp.2008.1480.1486

Bai, B., Brewer, K., Pearl, S., GailSwerdlow, S. (2006). Job Satisfaction, Organizational Commitment, and Internal Service Quality: A Case Study of Las Vegas Hotel/Casino Industry. Journal of Human Resources in Hospitality \& Tourism, 5(2), 37-54. http://dx.doi.org/10.1300/J171v05n02_03

Chang, C., \& Chang, H. (2009). Perceptions of internal marketing and organizational commitment by nurses. Journal of Advanced Nursing, 32, 16-39.

Çoban, S., \& Perçin, N. (2011). The Effects of factors of internal marketing on the components of organizational commitment in four and five star hotels. E-Journal of New World Sciences Academy, 6(2), 202-217.

Dennis, J. C. (1995). The Managerial Implications of the Learning Organization: A New Tool for Internal Marketing. Journal of Services Marketing, 9, 43-51. http://dx.doi.org/10.1108/08876049510094513

Gronross, C. (1994). The Service Quality Model and its Marketing Implications. European Journal of Marketing, 18, 36-44. http://dx.doi.org/10.1108/EUM0000000004784 
Kotler, P., \& Armstrong, C. (2007). Principles of Marketing (11th ed.).

Lee, C., \& Chen, W. J., (2006). The effect of internal marketing and organizational culture on knowledge management in the information technology industry. International Journal of Management, 24, 661-672.

Tsai, Y. F., \& Tang, T. W. (2008). How to improve service quality: Internal marketing as a determining factor. Total Quality Management, 19(11), 1117-1126. http://dx.doi.org/10.1080/14783360802323479

\section{Copyrights}

Copyright for this article is retained by the author(s), with first publication rights granted to the journal.

This is an open-access article distributed under the terms and conditions of the Creative Commons Attribution license (http://creativecommons.org/licenses/by/3.0/). 